\title{
The Divorced Library Worker
}

\author{
John J. Miniter
}

The performance of an employee on the job will be affected by many events or circumstances, some of which are clearly out of the supervisor's province and in many cases even beyond control of the employee himself. These events or circumstances have been well documented in the literature. Family problems, sickness of minor children, employee illness, economic problems, stress, commuting failures, and even the conduct of the supervisor ${ }^{1}$ have been cited as contributing to the employee's failure to perform adequately when all evidence indicates that the employee should successfully accomplish the job.

\section{New Study}

One study has indicated that marital problems leading to divorce will contribute substantially to absences, tardiness, and to voluntary terminations. The study by Kriegsmann and $\mathrm{Hardin}^{2}$ was conducted with eighty-eight male, blue-collar, white-collar, and professional subjects in the Chicago area. During the period of divorce, the men were absent an average of nearly sixteen days and more than twenty-five percent of the individuals replying to the questionnaire reported that they changed jobs before, during, or immediately after the divorce. The study while leaving some unanswered questions arouses one's interest in the problems of the divorced worker. One can speculate also on the reasons for the small percentage of return $(22 \%)$ since the sample of men had been prequalified as divorced.

This study, the only one this writer has discovered which deals with divorce and the workplace, holds significant interest for library personnel management and librarianship generally. Men may dominate this field at the top, but they are a small minority of the total library workforce. How do women react to divorce while working? Are there significant Sex differences? How does divorce affect the library workplace?

\footnotetext{
John J. Miniter is associate professor of library science, Texas Women's University, Denton, Texas.
}

The nation is currently experiencing a high divorce rate although the rate of divorce declined somewhat in 1982 from the rate reported for the year 1981. In 1982 approximately $1,180,000$ couples divorced while 2,495,000 marriages were performed. According to the Monthly Vital Statistics Report, North Carolina experienced 51,023 marriages in 1982 while the state reported a total of 29,715 divorces for the same period. ${ }^{3}$ Thus, divorces approximated fifty-eight percent of North Carolina marriages for the year. Naturally, since library workers are people (despite what some clients might think) library staff members are also subject to the painful rigors of an impending divorce and the possibly more painful aftereffects of the divorce court proceedings.

What are the effects of divorce, if any, on library staff personnel and their work? This study was organized as a pilot effort to learn about divorce in the workplace and it is the intention of the writer to refine the inquiry instrument and then conduct a wider study at a later time. While the present study suffers, as did the Kreigsmann and Hardin, from a low response rate, there were revealed, nonetheless, a number of interesting aspects of the subject and these are offered to the reader. The low return rate prohibited the use of Chi Square cross-tabulation of the data and so only descriptive statistics have been employed.

\section{Methodology}

A graudate student employing established random sampling techniques chose the names of three hundred individuals from the 1980 Texas Library Association membership directory. These people, whose names remained unknown to the researcher, were sent a covering letter, an inquiry form titled "Summary Sheet for Divorced Worker" and a return postpaid, preaddressed envelope. Neither the inquiry form nor the envelope was coded in any way. No follow-up letter was thus possible, but the writer felt that the sensitive subject matter 
of the study demanded that the addresses be assured of their anonymity, which was presumably guaranteed by these techniques. Another form, "Summary Sheet for Fellow Employee of Divorced Worker," was sent together with a covering letter and return post-paid, preaddressed envelope to one hundred individuals also chosen by random sample techniques. These items were not coded and no follow-up letter was employed to enhance the return.

One hundred and twenty-eight summary sheets for divorced workers were returned for a return rate of $42.6 \%$. Of that number, sixty-eight were not completed because the addressee had never experienced divorce. Sixty employable summary sheets were returned from people who had experienced divorce for a net usable return of twenty percent. Forty-nine of the summary sheets for fellow employees of divorced workers were returned for a somewhat disappointing forty-nine percent. Twenty of those were completed by people who had worked with a divorced fellow employee for a net usable return of twenty percent.

A discussion of the return rates is in order. The subject of divorce is extremely personal and many people have an understandable reluctance to reveal or to reconsider a sensitive interval of their lives or the life of a fellow worker. Many divorced respondents stated that no fellow worker knew of their divorce; many moved to another area following the divorce. Also, certain individuals or fellow workers view it as repugnant to reply to an inquiry which is concerned with divorce. Many others presumably did not reply because they choose never to reply to inquiries.

The employable return of twenty percent from a purely random sample, nevertheless, compares extremely favorably with the twentytwo percent rate of return reported by Kriegsmann and Hardin since Kreigsmann and Hardin employed as a sample known divorced males.

Of the sixty library workers whose returns were employed in the study, fifty-four (90\%) were female while six $(10 \%)$ were males. No significant difference in responses was discovered between male and female respondents. Three of the respondents were employed in clerical posts while forty-six declared themselves to be professional and eleven stated that they were managerial. All of the males declared themselves to be managers or professionals.

The fifty-four females and six males averaged 45.4 years old. They had been, on average, 22.6 years old at marriage. The individuals had been married an average of fifteen years, but the range stretched from one to thirty-two years.

\section{Job Change}

With reference to job change, twenty-nine $(48.3 \%)$ of the divorced individuals reported that they had changed jobs in the time period before, during, or after the divorce. This percentage is significantly higher than the percentage reported in the Kriegsmann and Hardin study. The percentage of those who sought new jobs is further skewed by an unknown amount since some of the divorced individuals were not employed during the period of the divorce. Eight of the individuals sought new jobs before the divorce; eight changed jobs during the divorce; and thirteen, or $44 \%$, of the respondents waited until after the divorce to change jobs.

The implication for personnel managers and chief librarians is quite clear: If an employee engages in a divorce action, there is about a $50 / 50$ possibility that that employee will seek a job elsewhere. The job change will occur independently of the individual's views of the job or the library. Nonetheless, the library will have to engage in the costly task of replacing that individual.

One could speculate on the reasons for the termination rate: $\mathrm{A}$ few reasons which appear to merit consideration are: (1) The individual cannot any longer support himself/herself and possible dependents on the salary presently gained. (2) The atmosphere of the library is now too uncomfortable for the individual. (3) The individual wishes to make a complete break with the past and seek a new beginning. (4) The individual wishes to return to his/her home town to be with family or friends.

\section{Work Patterns}

In the matter of absences from work before, during, or immediately after the period of the divorce, nineteen, or $31.7 \%$, of those reporting stated that they had missed at least one day and as many as four or more days before the divorce. Twenty-eight or $46.7 \%$, reported being absent at least one day and up to as many as four or more days during the divorce. After the divorce twelve individuals or $20 \%$ reported missing one day to as much as four or more days. In contrast to this, one woman volunteered the information that she took two hours of annual leave one afternoon to go to court for the divorce proceed- 
ings. Others volunteered the information that they couldn't afford to stay out of work because of financial obligations. This may help to explain the differences in job absences between the Kriegsmann and Hardin study and the present one. Also operating here may be the sex difference in coping with adversity. Is it possible that women are better able to cope with everyday living than are males?

When asked about their work efficiency, eighteen, or $30 \%$ of those responding felt that their efficiency had declined. These individuals also reported that it took them up to seven or more months to recover their original efficiency.

A companion question asked the respondents if they had suffered a decline in self-concept and, if so, how long it had taken to recover that self-concept. Thirty-four stated that they had indeed experienced such a decline. Of these, nineteen, or $56 \%$, stated that they had required up to one year to recover their selfconcept; while fifteen, or $44 \%$, stated that it required between one and two years time to recover their self-concept. Clearly, this is an important item for the supervising librarian to consider since people with impaired selfconcepts are not likely to initiate or prosecute new projects or even approach their old work with near as much application and interest as heretofore. They will almost certainly benefit from an understanding and supportive supervisor. Moreover, these people during any subsequent interview process when seeking a new job will often project themselves poorly when, indeed, they may be potentially very fine employees.

As noted earlier, the number of fellow employees of divorced workers who returned in quiries was quite small. Just twenty returns were employable. One hesitates to report the results of a twenty-unit sample in such a sensitive and subjective area as is the subject of this study. Thus, the author has merely summarized the results of this part of the inquiry.

Seventeen of the nineteen people responding to a question relating to obvious changes in the divorcing library staff member, noted a change in the individual. These changes related to regularity of attendance and other matters. Nine of the people responding reported more tardiness of their fellow worker while thirteen of the twenty reported that the divorcing individual was more frequently absent. This is generally in keeping with the reports of divorcing library staff members.
In terms of work habits, thirteen of the respondents reported that they detected decreased capacity for work among the divorcing people. Ten of the respondents reported decreased accuracy by the worker while fifteen reported a marked decrease in patience among the divorcing workers. The observing fellow workers reported that the divorcing worker in fifteen instances appeared to want or need more assurance while in thirteen instances the individual appeared to want or need more approval.

In terms of overall worker productivity, four respondents reported that their fellow workers maintained their productivity, but in ten instances productivity of the worker decreased by ten percent while four fellow workers reported a twenty percent drop in productivity by the divorcing person. Although these reports are merely observations by fellow workers and are subjective in nature, they do appear to offer support for the returns received from the sample of divorced workers.

\section{Summary and Conclusion}

Because of its disruptive effect, divorce is increasingly becoming an important component in the conduct of personnel management in organizations, including libraries. The divorcing worker will often change attendance habits, experience curtailed performance on the job, lower his/her productivity, and perhaps lose the ability to relate to fellow employees and clients. A person's self-concept may diminish perhaps for months or longer thus adding to the person's inability to successfully cope with the job. To add further to the problems of the library personnel manager, the worker, in a considerable number of cases, will leave the present employer who will then be forced to begin the employment process anew.

In the light of the possible traumatic effect of divorce on the library employee and the lesser effect the employee has on his/her fellow workers and clients as revealed in the preliminary study, additional research should be undertaken to confirm or deny the alleged importance of the phenomenon of divorce in the workplace.

\section{References}

1. J. A. Smith, "Occupational stress and emotional illness." Journal American Medical Association. 161 (1956): 1038-40. 2. J. K. Kriegsmann and D. R. Hardin, "Does Divorce Hamper Job Performance?" Personnel Administrator. (March-April, 1974), pp. 26-28.

3. National Center for Health Statistics. Monthly Vital Statistics Report. Vol. 31, No. 12 (March 14, 1983): 6. 